Deutsche Klassiker im Nationalsozialismus 
This page intentionally left blank 


\section{Deutsche Klassiker im Nationalsozialismus}

\section{Schiller $\cdot$ Kleist $\cdot$ Hölderlin}

Herausgegeben von Claudia Albert

Verlag J. B. Metzler Stuttgart - Weimar 
Die Deutsche Bibliothek - CIP-Einheitsaufnahme

Deutsche Klassiker im Nationalsozialismus: Schiller, Kleist, Hölderlin/hrsg. von Claudia Albert. - Stuttgart; Weimar: Metzler, 1994

(Metzler-Studienausgabe)

ISBN 978-3-476-00985-2

NE: Albert, Claudia [Hrsg.]

ISBN 978-3-476-00985-2

ISBN 978-3-476-03520-2 (eBook)

DOI 10.1007/978-3-476-03520-2

Dieses Werk einschließlich aller seiner Teile ist urheberrechtlich geschützt. Jede Verwertung außerhalb der engen Grenzen des Urheberrechtsgesetzes ist ohne Zustimmung des Verlages unzulässig und strafbar. Das gilt insbesondere für Vervielfältigungen, Übersetzungen, Mikroverfilmungen und die Einspeicherung und Verarbeitung in elektronischen Systemen.

(ㄷ) 1994 Springer-Verlag GmbH Deutschland

Ursprünglich erschienen bei J. B. Metzlersche Verlagsbuchhandlung und Carl Ernst Poeschel Verlag GmbH in Stuttgart 1994 


\section{Inhaltsverzeichnis}

Claudia Albert

Einleitung $\ldots \ldots \ldots \ldots \ldots \ldots \ldots \ldots \ldots \ldots \ldots \ldots \ldots \ldots$

\section{SCHILLER}

Gabriele Stilla

Gerhard Fricke: Literaturwissenschaft als

Anweisung zur Unterordnung . . . . . . . . . . . . . . 18

1941: Der »Kriegseinsatz der Geisteswissenschaften« . . . . . . . . . 37

Claudia Albert

Schiller als Kampfgenosse? . . . . . . . . . . . . . . . . . 48

Philologie oder Deutung . . . . . . . . . . . . . 50

Grenzen der Vermittlung . . . . . . . . . . . . . . 57

Das Schiller-Jubiläum 1934 . . . . . . . . . . . . . . . . . . 67

KLEIST

Marcus Gärtner

Stationen der Kleist-Rezeption nach 1933 . . . . . . . . . . . 77

Das Kleist-Jubiläum $1936 \ldots$. . . . . . . . . . . . . . 85

Mechthild Kirsch

Die Bochumer Festwoche . . . . . . . . . . . . 86

Marcus Gärtner

Journalistische Beiträge . . . . . . . . . . . . . . . . . . 99 
Kleistbilder und Kleistdeutungen

in der Germanistik . . . . . . . . . . . . . . . . . . . 105

Strategien der Aneignung . . . . . . . . . . . . . . . . . 132

\section{Marike Werner}

"Michael Kohlhaas« als Modellfall

Interpretationen der 20er Jahre . . . . . . . . . . . . . . . . . 136

Interpretationselemente $\mathrm{zu} »$ Michael Kohlhaas« . . . . . . . . . . . 145

Die Existenz des »Michael Kohlhaas« bei

Hermann Pongs . . . . . . . . . . . . . . . . . . . 156

Der Existenzbegriff als literatur-

wissenschaftliches Deutungsmuster . . . . . . . . . . 167

Martin Vöhringer

Hermann Pongs und das Konzept einer existentiellen

Literaturwissenschaft . . . . . . . . . . . . . . . . . . . 171

\section{HöLDERLIN}

\section{Claudia Albert}

Sakralisierung der Dichtergestalt . . . . . . . . . . . . . . . . . 189

Heideggers Hölderlin-Deutung und ihre Rezeption . . . . . . . . 209

Treue zum Text oder Bekenntnis zum Dichter . . . . . . . . . . . 216

Hölderlin im »Totalen Krieg« . . . . . . . . . . . . . . . . . . 227

Form als Haltung: Hölderlin-Epigonen . . . . . . . . . . . 236

Nachwort

Abstand, nicht Widerstand: Max Kommerell . . . . . . . . 249

Anhang . . . . . . . . . . . . . . . . 254 